\title{
Knowledge, attitude, and beliefs toward group behavior therapy programs among male adults attending smoking cessation clinics, cross-sectional analysis
}

Shatha A. Alduraywish ${ }^{1,2^{*}}$, Meaad F. Alnofaie ${ }^{3}$, Balqes F. Alrajhi ${ }^{3}$, Fatima A. Balsharaf ${ }^{3}$, Sarah S. Alblaihed ${ }^{3}$, Alaa A. Alsowigh ${ }^{3}$, Wafa S. Alotaibi ${ }^{3}$ and Fahad M. Aldakheel ${ }^{2,4}$

\begin{abstract}
Background: Group therapy assists individuals in learning many behavioral techniques for smoking cessation and providing each other with mutual support. Group behavior therapy is not routinely provided as a modality of tobacco cessation assistance in tobacco cessation clinics in Saudi Arabia despite it is effectiveness. Therefore, this study aimed to assess the knowledge, attitude, and beliefs toward group behavior therapy programs among male adults who attend smoking cessation clinics and to identify the associated factors.

Methods: A cross-sectional study was conducted with a targeted sample of 229 males aged 18 and above who were attending smoking cessation clinics. The participants were randomly selected. Data were collected using a paper-based questionnaire. One-way ANOVA and chi-square test were used for statistical analysis.

Results: Results showed a high percentage of the study participants were in the age group of 21-40 years. Most of them were consuming 10-20 cigarettes per day. Around 79\% of the participants had previous attempted to quit smoking. This study demonstrated a deficit in knowledge about group behavior therapy. The mean score for attitude and beliefs was 5.3 out of 11. Multiple factors influenced their attitudes and beliefs, such as previous attempts to quit smoking ( $p$-value $<0.05$ ) and the number of cigarettes used per day ( $p$-value $=0.03$ ). The knowledge was found to be affected by the level of education ( $p$-value $=0.04$ ).

Conclusion: The study demonstrates a deficit in knowledge about group behavior therapy and it shows that the level of education was associated with the knowledge. Additionally, previous attempts to quit smoking and the number of cigarettes used per day, influenced the participants' attitude and beliefs toward group behavioral therapy. Increase awareness about the role of group behavior therapy in smoking cessation is required before this method is implemented in the routine practice.
\end{abstract}

Keywords: Attitude, Behavioral therapy, Beliefs, Group therapy, Knowledge, Smoking cessation

\footnotetext{
* Correspondence: salduraywish@ksu.edu.sa

'Department of Family and Community Medicine, College of Medicine, King Saud University, Riyadh, Saudi Arabia

${ }^{2}$ Prince Sattam bin Abdulaziz Research Chair for Epidemiology and Public Health, College of Medicine, King Saud University, Riyadh, Saudi Arabia

Full list of author information is available at the end of the article
}

(c) The Author(s). 2021 Open Access This article is licensed under a Creative Commons Attribution 4.0 International License, which permits use, sharing, adaptation, distribution and reproduction in any medium or format, as long as you give appropriate credit to the original author(s) and the source, provide a link to the Creative Commons licence, and indicate if changes were made. The images or other third party material in this article are included in the article's Creative Commons licence, unless indicated otherwise in a credit line to the material. If material is not included in the article's Creative Commons licence and your intended use is not permitted by statutory regulation or exceeds the permitted use, you will need to obtain permission directly from the copyright holder. To view a copy of this licence, visit http://creativecommons.org/licenses/by/4.0/ The Creative Commons Public Domain Dedication waiver (http://creativecommons.org/publicdomain/zero/1.0/) applies to the data made available in this article, unless otherwise stated in a credit line to the data. 


\section{Background}

Smoking is one of the leading public health concerns [1]. Globally, almost $23 \%$ of adults smoke tobacco products; this includes more than 1 billion males and 250 million females [2]. In Saudi Arabia, a recent study that assessed the prevalence of smoking among adults showed that the prevalence of cigarette smoking was around $21.4 \%$ in 2018 [3]. It has been shown that smoking is considered a significant risk factor for developing several chronic diseases such as pulmonary disease, heart disease, and lung cancer [4]. The World Health Organization recognized tobacco as the second leading risk factor for death worldwide [5]. Therefore, implementing smoking cessation strategies would assist in reducing the burden of these diseases.

Many approaches have been utilized for smoking cessation. The biopsychosocial approach has been proven to increase the rate of smoking cessation. This approach includes pharmacological and non-pharmacological interventions. Pharmacological treatment includes nicotine replacement therapy (NRT), Bupropion, and Varenicline (Champix/Chantix). The non-pharmacological interventions include considering the positive and negative environmental factors that might play a role in the effectiveness of treatment [6]. Several studies have shown the significant impact of combining pharmacological approaches with supportive intervention in successful smoking cessation [7]. One of these studies showed an increase in chance from 70 to $100 \%$ to quit smoking [8].

Additionally, smoking has a behavioral component related to physical addiction to nicotine. Behavioral intervention improved long-term smoking cessation. There are a variety of behavioral therapy interventions, including individual behavioral counseling, brief advice/interventions, telephone counseling, open-group forms of behavioral therapy, and closed-group forms of behavioral therapy. However, open-group forms of behavioral therapy are better and more cost-effective compared to the other types [9-11].

Previous studies showed that group therapy assists individuals in learning many behavioral techniques for smoking cessation and providing each other with mutual support [12-14]. A recent Cochrane review that assessed the group behavior therapy programmes for smoking cessation concluded that group therapy is considered superior than self-help and other less intensive intervention in smoking cessation. However, the review demonstrated lack of evidence for assessing the effectiveness for group therapy compared to intensive individual counselling [12]. Another review that assessed the usefulness and advantages of group behavior therapy among smokers, conclude that group intervention should be incorporated the management plan for smoking cessation wherever possible, because it is generally more efficient that individual intervention [13].

A study from Canada in 2002 aimed to assess the efficacy of other partner support groups in smoking cessation; they found that people who received partner group support had a higher cessation rate [15]. Another randomized clinical trial conducted in China studied the effectiveness of group intervention in smoking cessation among smokers and found that group intervention was highly effective compared to the control group [16]. In addition, behavioral counseling was found to be highly effective therapy [12].

As part of Saudi Vision 2030, the government of Saudi Arabia is determined to enhance the quality of preventive and therapeutic healthcare services. The recent prevalence of tobacco uses and its consequences are among the major public health concerns in Saudi Arabia. Tobacco control is urgently needed in the country due to increasing in the number of smokers and its related deaths. It has been estimated that around 70,000 Saudis die from smoking-related diseases every year [17].

The Ministry of health in Saudi Arabia has established the Tobacco Control Program in 2002. This program offers several services related to all aspects of smoking awareness, its harms and methods to combat it. Additionally, it provides a series of smoking cessation clinics located in many cities around the country [18]. These clinics equipped with trained personnel, to offer free consultation as well as provision of free pharmacological treatment. Group behavior therapy is not provided as a modality of tobacco cessation assistance although it has been shown to be effective in previous studies. Understanding the knowledge, attitude and beliefs of people attending the smoking cessation clinics toward group behavior therapy would guide the decision maker to integrate this method in the smoking cessation services.

Since the application of group behavior therapy programs in Saudi Arabia is lacking, the aim of the current study was to understand the knowledge, attitude, and beliefs toward group behavior therapy programs and its associated factors.

\section{Methods}

\section{Study design and study participants}

A cross-sectional study was conducted in five governmental smoking cessation clinics from different areas in Riyadh, Saudi Arabia. These clinics are Aldiryah, Alezdehar, Alrowdah, Alaziziyah neighborhoods, and Imam Abdulrhman Alfaisal Hospital. This study was carried out from November 2019 to March 2020.

The inclusion criteria were as follows: adult males who attended smoking cessation clinics planning to quit smoking or follow-up regarding their smoking cessation treatment. The females were excluded from this study 
because the prevalence of Saudi female smokers was estimated to be around $1.5 \%$ according to a national health survey [19]. Additionally, women rarely attended smoking cessation clinics. The participants were selected randomly through a simple random sampling technique using a computer-generated patients' list in the smoking cessation clinics to minimize bias.

\section{Sample size estimation}

As there were no previous studies that assessed the knowledge, attitude, and beliefs toward group behavior therapy programs, a pilot study was conducted to estimate the sample size. Results from this pilot study showed that the level of knowledge was approximately $42.2 \%$.

Using the single proportion formula $\left(n=Z^{2} \alpha \frac{P(1-p)}{d^{2}}\right)$, the estimated sample size for the study was 191 smokers, considering the $20 \%$ non-response rate out of a total of 229 smokers.

\section{Data collection}

The data were collected using paper-based questionnaires distributed randomly to the people attending the smoking cessation clinics. The questionnaire was developed using previously published information [13, 20]. It was reviewed by two experts in the field, MA (Pulmonology Consultant) and MG (Family Physician), both are tobacco treatment specialists. The questionnaire included four sections: the first section contained sociodemographic information (age, economic status, and educational level). The second section focused on tobacco use behavior (previous attempts to quit, number of cigarettes per day, duration of tobacco use). The third section focused on knowledge about group behavior therapy programs. The fourth section was about attitudes and beliefs regarding group behavior therapy programs.

\section{Data analysis}

The data were analyzed using SPSS 24.0 Version Statistical Software [21]. Percentages and frequencies were used to describe sociodemographic factors and knowledge. For attitude and beliefs, a standardized score was generated in SPSS with 1 point given for positive attitude and 0 points for negative attitude. If the total score was more than five, then, the participant had a positive attitude and positive beliefs, and if it was less than five, the participant had a negative attitude and beliefs. These scores were reported as the mean and standard deviation. One-way ANOVA was used to estimate the level of significance for the differences between the continuous variables and the chi-square test for categorical variables.

\section{Results}

\section{Participants' characteristics}

The total number of completed questionnaires that were distributed in pre-defined smoking cessation in Riyadh was 229. Most of the participants aged between 21 and 40 years were well educated (Table 1).

Around $79 \%$ of participants had previously attempted to quit smoking, and most of them had more than two attempts (38.4\%). About half of the participants smoked $10-20$ cigarettes per day, and $30.1 \%$ of them had been smokers for 11 to 20 years (Table 2).

\section{Knowledge about group behavioral therapy for smoking cessation and its associated factors}

Results from the current study showed a deficit in the knowledge about group behavior therapy (Table 3). Moreover, about half of them agreed to a certain degree that this type of treatment was appropriate to quit smoking. Having a high level of education was related to knowledge of group behavior therapy. The group in which $61.1 \%$ of people had higher education degrees

Table 1 Sociodemographic characteristics for study participants

\begin{tabular}{|c|c|}
\hline Characteristics & $\begin{array}{l}N=229 \\
\mathrm{n}(\%)\end{array}$ \\
\hline \multicolumn{2}{|l|}{ Age (Years) } \\
\hline$\geq 18-<20$ & $15(6.6)$ \\
\hline$\geq 20-<30$ & $81(35.4)$ \\
\hline$\geq 30-<40$ & $74(32.3)$ \\
\hline$\geq 40-<50$ & $31(13.5)$ \\
\hline$\geq 50$ & $28(12.2)$ \\
\hline \multicolumn{2}{|l|}{ Educational level } \\
\hline Unable to read and write & $6(2.6)$ \\
\hline High school or less & $70(30.6)$ \\
\hline Bachelor & $98(42.8)$ \\
\hline Diploma & $37(16.2)$ \\
\hline Higher educational Degree & $18(7.9)$ \\
\hline \multicolumn{2}{|l|}{ Income $\left(\mathrm{SR}^{\mathrm{a}}\right)$} \\
\hline$\leq 5000$ & $68(29.7)$ \\
\hline$>5000-\leq 10,000$ & $69(30.1)$ \\
\hline$>10,000-\leq 15,000$ & $63(27.5)$ \\
\hline$>15,000$ & $29(12.7)$ \\
\hline \multicolumn{2}{|l|}{ Job } \\
\hline Having job & $184(80.3)$ \\
\hline Don't have job & $19(8.3)$ \\
\hline Student & $26(11.4)$ \\
\hline \multicolumn{2}{|l|}{ Residency } \\
\hline Riyadh & $213(93)$ \\
\hline Others & $16(7)$ \\
\hline
\end{tabular}

${ }^{a} S R$ Saudi Riyals 
Table 2 Tobacco use behavior for study participants

\begin{tabular}{ll}
\hline Characteristics & $\begin{array}{l}\boldsymbol{N}=\mathbf{2 2 9} \\
\mathbf{n}(\%)\end{array}$ \\
\hline Previous attempts to quit & $181(79)$ \\
Yes & $48(21)$ \\
No & \\
Number of attempts & $35(15.3)$ \\
Once & $62(27.1)$ \\
Twice & $88(38.4)$ \\
More than two & $44(19.2)$ \\
Never & \\
Type of tobacco & $177(77.3)$ \\
Cigarettes & $36(15.7)$ \\
Electronic tobacco & $1(0.4)$ \\
Chewing & $12(5.2)$ \\
Cigarettes and Electronic & $1(0.4)$ \\
Cigarettes and chewing & $2(0.8)$ \\
Chewing, Electronic and other & \\
Cigarettes per day & $71(31)$ \\
$<10$ cigarettes & $111(48.5)$ \\
$10-20$ cigarettes & $47(20.5)$ \\
$>20$ cigarettes & \\
Years of smoking & $20(8.70)$ \\
$\leq 1$ & $42(18.3)$ \\
$>10-\leq 5$ & $58(25.3)$ \\
\hline & $40(17.5)$ \\
\hline
\end{tabular}

knew the meaning of group behavior therapy. Therefore, the level of education was significantly associated with knowledge about group behavioral therapy $(p=0.04)$ (Table 4). There were no significant associations between age, income, previous attempts to quit smoking, number of cigarettes used per day, duration of years in tobacco use, and knowledge of group behavioral therapy.

Table 3 Knowledge about group behavior therapy programs for smoking cessation

\begin{tabular}{lll}
\hline Knowledge variable & & $\begin{array}{l}\boldsymbol{N}=\mathbf{2 2 9} \\
\mathbf{n}(\%)\end{array}$ \\
\hline $\begin{array}{l}\text { 1- Do you know what is group } \\
\text { behavior therapy? }\end{array}$ & Yes & $81(35.4)$ \\
$\begin{array}{l}\text { 2- Have you ever heard about } \\
\text { these programs? }\end{array}$ & Yes & $148(64.6)$ \\
$\begin{array}{l}\text { 3- Do you think this type of } \\
\text { treatment is appropriate to } \\
\text { quit smoking? }\end{array}$ & Nos & $89(38.9)$ \\
& Yes, to certain degree & $140(61.1)$ \\
& No & $66(28.8)$ \\
& I don't know & $17(71.5)$ \\
\hline
\end{tabular}

Attitude and beliefs toward group behavioral therapy for smoking cessation

The mean score for attitude and beliefs toward group behavioral therapy was $5.3 \pm 2.06$ (Fig. 1). Participants who had previous attempts to quit smoking showed a positive attitude and beliefs toward behavioral therapy $(p=0.05)$. In addition, smokers who consumed less than 10 cigarettes per day showed a positive attitude and beliefs toward behavioral therapy. This result implies that the number of cigarettes used per day influences the attitude and beliefs of the participants toward the group behavioral therapy ( $p=0.03$ ) (Table 5$)$. Nevertheless, the association of sociodemographic factors and smoking behavior with attitudes and beliefs toward group behavioral therapy showed no significant association between age, level of education, income, years of smoking, and attitudes and beliefs.

\section{Discussion}

The findings confirm a deficit in knowledge about group behavior therapy. This might be due to the unavailability of this therapy approach in Saudi Arabia and the social barrier of smoking stigma in our community. Regarding the factors associated with knowledge deficit, it is clear that the level of education was associated with their knowledge. In addition, previous attempts to quit smoking and the number of cigarettes used per day, influenced the participants' attitude and beliefs toward group behavioral therapy. Otherwise, there was no significant association between sociodemographic factors and smoking behavior with attitudes and beliefs toward group behavioral therapy.

However, a study found that smoking cessation success differed from country to country due to socioeconomic, personal, and political reasons. In addition, they found that age and income both have an association with success in smoking cessation. According to their study, as income increases the most positive effect on participants to quit smoking and success in cessation. In addition, as age increases, success in cessation increases, especially in the lower-education group [22].

It has been found that most of the respondents were young males; $79 \%$ of them had had attempted to quit smoking multiple times. In line with a previous study conducted in Makkah, $70.2 \%$ had tried at least once to quit smoking [23]. Another study that studied public knowledge and attitudes regarding smoking and smoking cessation treatments in New Zealand showed that $86 \%$ of the participants tried to quit smoking at least once [20]. Consequently, $78.3 \%$ of those who previously attempted to quit smoking started from one attempt to six attempts [18]. From these results, it is clear that the failure in smoking cessation programs could be a result 
Table 4 Knowledge toward group behavioral therapy for smoking cessation according to different sociodemographic characteristics and tobacco use behavior

\begin{tabular}{|c|c|c|c|c|}
\hline Variables & $\begin{array}{l}\text { Do you know what is } \\
\text { group behavior therapy? } \\
\text { (yes) } \\
\mathrm{n}(\%)\end{array}$ & $p$ values* & $\begin{array}{l}\text { Have you ever heard } \\
\text { about these programs? } \\
\text { (yes) } \\
\text { n (\%) }\end{array}$ & $p$ values* \\
\hline \multicolumn{5}{|l|}{ Age (years) } \\
\hline$\geq 18-<20$ & $4(26.7)$ & 0.50 & $5(33.3)$ & 0.20 \\
\hline$\geq 20-<30$ & $29(35.8)$ & & $33(40.7)$ & \\
\hline$\geq 30-<40$ & $31(41.9)$ & & $35(47.3)$ & \\
\hline$\geq 40-<50$ & $10(32.3)$ & & $8(25.8)$ & \\
\hline$\geq 50$ & $7(25.0)$ & & $8(28.6)$ & \\
\hline \multicolumn{5}{|l|}{ Education } \\
\hline Unable to read and write & $2(33.3)$ & 0.04 & $2(33.3)$ & 0.08 \\
\hline High school or less & $17(24.3)$ & & $20(28.6)$ & \\
\hline Bachelor & $39(39.8)$ & & $43(43.9)$ & \\
\hline Diploma & $12(32.4)$ & & $13(35.1)$ & \\
\hline Higher educational Degree & $11(61.1)$ & & $11(61.1)$ & \\
\hline \multicolumn{5}{|l|}{ Income $\left(\mathrm{SR}^{\mathrm{a}}\right)$} \\
\hline$\leq 5000$ & $19(27.9)$ & 0.46 & $24(35.3)$ & 0.79 \\
\hline$>5000-\leq 10,000$ & $27(39.1)$ & & $29(42.0)$ & \\
\hline$>10,000-\leq 15,000$ & $23(36.5)$ & & $26(41.3)$ & \\
\hline$>15,000$ & $12(41.4)$ & & $10(34.5)$ & \\
\hline \multicolumn{5}{|l|}{ Previous attempts to quit } \\
\hline Yes & $64(35.4)$ & 0.10 & $68(37.6)$ & 0.44 \\
\hline No & $17(35.4)$ & & $21(43.8)$ & \\
\hline \multicolumn{5}{|l|}{ Cigarettes per day } \\
\hline$<10$ cigarettes & $29(40.8)$ & 0.23 & $29(40.8)$ & 0.74 \\
\hline 10-20 cigarettes & $40(36.0)$ & & 44 (39.6) & \\
\hline$>20$ cigarettes & $12(25.5)$ & & $16(34.0)$ & \\
\hline \multicolumn{5}{|l|}{ Years of smoking } \\
\hline$\leq 1$ & $7(35.0)$ & 0.97 & $7(35.0)$ & 0.97 \\
\hline$>1-\leq 5$ & $15(35.7)$ & & $18(42.9)$ & \\
\hline$>5-\leq 10$ & $20(34.5)$ & & $22(37.9)$ & \\
\hline$>10-\leq 20$ & $23(33.3)$ & & $26(37.7)$ & \\
\hline$>20$ & $16(40.0)$ & & $16(40.0)$ & \\
\hline
\end{tabular}

* $p$ values from Chi-squared test, ${ }^{\text {a } S R ~ S a u d i ~ R i y a l s ~}$

of dependence on the pharmacological approach without any supportive intervention.

The current study revealed that the number of cigarettes used per day significantly influenced participants' attitude and beliefs toward group behavioral therapy. Results showed that smokers consumed 10-20 cigarettes per day. The last survey conducted by the Saudi Health Interview Survey in 2020 showed the daily use of cigarettes with an average of 15 cigarettes per day [19]. This indicates a decrease in tobacco consumption compared to previous years and reflects the efforts of smoking cessation clinics. It is necessary to highlight the conclusion of prior research that smokers who consumed more than 20 cigarettes per day dropped out more frequently in the initial group meetings $(p=0.031)$ [24]. From this standpoint, the consumption of cigarettes might be a vital factor that can determine relapses during therapy.

Smoking habits tend to be acquired at an early age and are significantly associated with a high prevalence of smoking [3]. Similarly, as shown in our results, the average onset of smoking is between 11 and 20 years. In the current study, it has been found that the mean age of smokers was 35. Additionally, if we assume the onset of smoking 20 years ago, the smoking age would be almost 


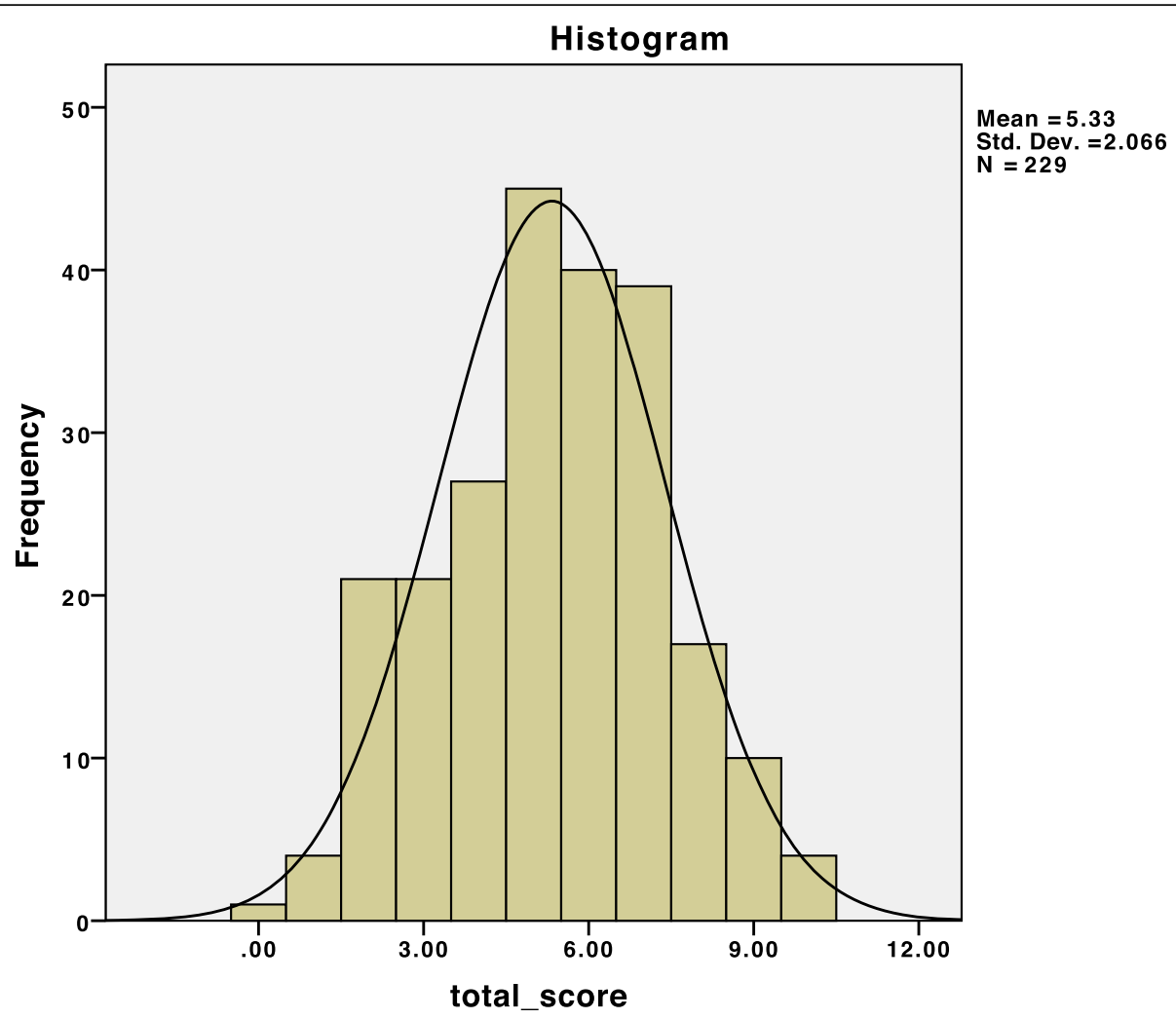

Fig. 1 The distribution of the score for attitude and beliefs toward group behavioral therapy

15 years, while the Saudi Health survey showed that the prevalence of smoking at the age of 15 years was 29 and $60.9 \%$ and that it started before 18 years $[19,25]$. Therefore, this emphasizes the implantation of awareness programs at a young age, as suggested in a previous study in Saudi Arabia, that the preventive programs should started in primary schools before the age of 13 [26]. This suggestion is consistent with what has been found in a previous study that concludes the significance of prevention programs to reinforce non-smoking perceptions and behaviors after using a random clinical trial to assess the effects on smoking initiation and changes in beliefs [27]. It is critical to note that another study that showed that adult smokers older than 35 years were more likely to adhere to treatment $(p=0.017)$ than younger smokers [24]. This implies that most of the smokers who seek help are adults.

Smokers who want to quit had less knowledge than what we assumed about group behavior therapy programs. The reason behind this can be related to the lack of application of group behavior therapy programs since the programs are mainly dependent on the pharmacological approach with limited psychosocial interventions. Nevertheless, results showed that the participants' level of education was significantly associated with their knowledge of this therapy approach. Although some participants were well educated, it did not affect their behavior. This finding was similar to that of a previous study [28].

In contrast, a study in Turkey found an association between level of education and success in smoking cessation. As the level of education had a greater positive effect on participants to quit smoking and progress in cessation. In addition, the higher the education level and age, the greater the success in cessation [22]. Hence, we suggest targeting the educated population while initiating these programs to obtain the ultimate results.

It is worth discussing these impressive results that previous attempts to quit smoking significantly influence the attitude and beliefs toward group behavioral therapy, which indicates that smokers encounter a serious problem with relapses. Additionally, the factors associated with success or failure to attempt smoking cessation showed that motivation is an essential factor in quitting smoking and maintaining cessation in the future [29, 30]. By reviewing the literature, many studies concur with the combination of pharmacological approaches with supportive intervention [7]. One study found an increase in chance from 70 to $100 \%$ to quit smoking [8]. In another review, a meta-analysis of 40 trials showed a significant benefit of the combination of pharmacological and behavioral therapy [31]. In 
Table 5 Association of sociodemographic characteristics with attitude and beliefs toward group behavioral therapy

\begin{tabular}{|c|c|c|c|}
\hline Sociodemographic characteristics & Mean (SD) & $\mathbf{F}$ & $p$-value* \\
\hline \multicolumn{4}{|l|}{ Age (years) } \\
\hline$\geq 18-<20$ & $4.73(2.31)$ & 1.79 & 0.13 \\
\hline$\geq 20-<30$ & $5.35(1.97)$ & & \\
\hline$\geq 30-<40$ & $5.14(2.14)$ & & \\
\hline$\geq 40-<50$ & $5.26(2.02)$ & & \\
\hline$\geq 50$ & $6.21(1.93)$ & & \\
\hline \multicolumn{4}{|l|}{ Education } \\
\hline Unable to read and write & $3.67(2.88)$ & 1.10 & 0.10 \\
\hline High school or less & $5.50(1.88)$ & & \\
\hline Bachelor & $5.12(1.98)$ & & \\
\hline Diploma & $5.86(2.32)$ & & \\
\hline Higher educational Degree & $5.28(2.19)$ & & \\
\hline \multicolumn{4}{|l|}{ Income $\left(S^{a}\right)$} \\
\hline$\leq 5000$ & $5.18(2.05)$ & 0.65 & 0.59 \\
\hline$>5000-\leq 10,000$ & $5.35(2.09)$ & & \\
\hline$>10,000-\leq 15,000$ & $5.60(2.16)$ & & \\
\hline$>15,000$ & $5.07(1.87)$ & & \\
\hline \multicolumn{4}{|l|}{ Previous attempts to quit } \\
\hline Yes & $5.52(2.00)$ & 7.76 & $<0.05$ \\
\hline No & $4.60(2.14)$ & & \\
\hline \multicolumn{4}{|l|}{ Cigarettes per day } \\
\hline$<10$ cigarettes & $5.80(2.12)$ & 3.28 & 0.03 \\
\hline 10-20 cigarettes & $5.01(2.11)$ & & \\
\hline$>20$ cigarettes & $5.38(1.76)$ & & \\
\hline \multicolumn{4}{|l|}{ Years of smoking } \\
\hline$\leq 1$ & $5.50(2.40)$ & 0.19 & 0.94 \\
\hline$>1-\leq 5$ & $5.48(2.16)$ & & \\
\hline$>5-\leq 10$ & $5.31(1.95)$ & & \\
\hline$>10-\leq 20$ & $5.17(2.03)$ & & \\
\hline$>20$ & $5.40(2.11)$ & & \\
\hline
\end{tabular}

${ }^{*} p$-value from one-way ANOVA test, ${ }^{\text {a }} S R$ Saudi Riyals

addition, a study conducted on female prisoners showed that the combination of behavior therapy and pharmacological therapy was efficient compared to control groups [32].

Other studies have shown that smokers failed due to social reasons or friends' influence (44\%) [33]. This factor leads us to a critical question associated with the failure of quitting smoking. Does the smoker need to establish group behavior therapy programs to overcome the social impact?

\section{Strength and limitation}

The strength of the current study is that it provides baseline information regarding knowledge, attitude, and beliefs toward group behavior therapy in our region. In addition, the study population was heterogeneous in terms of a previous attempt to quit smoking, which enriched the study findings. Furthermore, this study revealed the factors associated with the endorsement of a group behavior therapy program. On the other hand, the study has some limitations. The participants may not represent the Saudi population as the data were collected from five centers in Riyadh only. However, Riyadh is the capital city of the kingdom with a heterogeneous population from different socioeconomic classes. Moreover, the knowledge, attitude and beliefs toward group behavior therapy for smoking cessation were assessed only among male smokers. Lacking the relevant data on female might influence the findings. However, the prevalence of Saudi female smokers is low and they are less likely to attend the smoking cessation clinics compared to male. Another limitation is the scarcity of literature that assessed this topic internationally and the lack of previous studies in Saudi Arabia.

\section{Conclusion}

This study demonstrated a deficit in the knowledge of people attending smoking cessation clinics regarding the group behavior therapy. Moreover, it showed that multiple factors play a role in smokers' knowledge and attitudes, such as previous attempts to quit smoking, the number of cigarettes used per day, and the level of education. Although, The Ministry of Health in Saudi Arabia provided smoking cessation clinics in several regions around the country, these clinics mainly provide a pharmacological treatment. Group behavior therapy is not routinely provided as a modality of tobacco cessation assistance in these clinics. Despite the effectiveness of this method in smoking cessation, increase population awareness about the role of group behavior therapy in smoking cessation is required before this method is implemented in the routine practice.

\section{Supplementary Information}

The online version contains supplementary material available at https://doi. org/10.1186/s12889-021-10924-4.

\section{Additional file 1. The Questionnaire.}

\section{Acknowledgments}

The authors are grateful to the Deanship of Scientific Research, King Saud University, Riyadh, Kingdom of Saudi Arabia for funding through the Vice Deanship of Scientific Research Chairs. Also, the authors gratefully acknowledged the support from those who involved in data collection from the clinics; Rand AlRefaei, Sadeem AlHazmi, Sarah AlQuwayz, Muneerah AlSadhan, Mona Alomiriny, Tarfa Alsharidi, Renad Alhaqbani, Rawan Alzayed, Abdulrahman Alshabnan, Dana Naibulharam, and Abdulrahman Al-Mezaini.

Authors' contributions

SAA; overall supervision of research project, and reviewer of the manuscript. MFA, BFA, FAB, SSA, AAA, and WSA; review of literature, study design, data 
collection, data management and analysis, progress report, data analysis, final report and manuscript writing. FMA; data analysis, proofreading and editing. All authors contributed to read and approved the final manuscript.

\section{Funding}

The authors extend their appreciation to the Deanship of Scientific Research at King Saud University for funding this work through research group No (RG- 1441-465).

\section{Availability of data and materials}

The datasets used and analyzed during the current study are available from the corresponding author on reasonable request.

\section{Declarations}

\section{Ethics approval and consent to participate}

The study was approved by the King Saud University Institutional Review Board (E-19-4447).

The written informed consent was obtained from the all participants for the study.

All protocols are carried out in accordance with relevant guidelines and regulations.

\section{Consent for publication}

Not applicable.

\section{Competing interests}

The authors declare that they have no competing interests.

\section{Author details}

'Department of Family and Community Medicine, College of Medicine, King Saud University, Riyadh, Saudi Arabia. ${ }^{2}$ Prince Sattam bin Abdulaziz Research Chair for Epidemiology and Public Health, College of Medicine, King Saud University, Riyadh, Saudi Arabia. ${ }^{3}$ College of Medicine, King Saud University, Riyadh, Saudi Arabia. ${ }^{4}$ Department of Clinical Laboratory Sciences, College of Applied Medical Sciences, King Saud University, Riyadh, Saudi Arabia.

Received: 23 December 2020 Accepted: 19 April 2021

Published online: 05 May 2021

\section{References}

1. West R. Tobacco smoking: health impact, prevalence, correlates and interventions. Psychol Health. 2017;32(8):1018-36. https://doi.org/10.1080/ 08870446.2017.1325890.

2. Perez-Warnisher MT, de Miguel MPC, Seijo LM. Tobacco use worldwide: legislative efforts to curb consumption. Ann Glob Health. 2018;84(4):571-9. https://doi.org/10.29024/aogh.2362.

3. Algabbani AM, Almubark R, Althumiri N, Alqahtani A, BinDhim N. The prevalence of cigarette smoking in Saudi Arabia in 2018. Food Drug Regul Sci J. 2018;1(1):1.

4. Lushniak BD, Samet JM, Pechacek TF, Norman LA, Taylor PA. The health consequences of smoking - 50 years of progress: a report of the surgeon general; 2014

5. Organization WH. Global health risks: mortality and burden of disease attributable to selected major risks: World Health Organization; 2009.

6. McDonough M. Update on medicines for smoking cessation. Aust Prescr. 2015;38(4):106-11. https://doi.org/10.18773/austprescr.2015.038.

7. Clarke JG, Stein L, Martin RA, Martin SA, Parker D, Lopes CE, et al. Forced smoking abstinence: not enough for smoking cessation. JAMA Intern Med. 2013;173(9):789-94. https://doi.org/10.1001/jamainternmed.2013.197.

8. Stead LF, Koilpillai P, Fanshawe TR, Lancaster T. Combined pharmacotherapy and behavioural interventions for smoking cessation. Cochrane Database Syst Rev. 2016;3:CD008286.

9. Hiscock R, Murray S, Brose LS, McEwen A, Bee JL, Dobbie F, et al. Behavioural therapy for smoking cessation: the effectiveness of different intervention types for disadvantaged and affluent smokers. Addict Behav. 2013:38(11):2787-96. https://doi.org/10.1016/j.addbeh.2013.07.010.

10. De Bruin M, Viechtbauer W, Eisma MC, Hartmann-Boyce J, West R, Bull E, et al. Identifying effective behavioural components of intervention and comparison group support provided in SMOKing cEssation (IC-SMOKE) interventions: a systematic review protocol. Syst Rev. 2016;5(1):1-9.
11. Roberts NJ, Kerr SM, Smith SM. Behavioral interventions associated with smoking cessation in the treatment of tobacco use. Health Serv Insights. 2013;6(HSI):S11092.

12. Stead LF, Carroll AJ, Lancaster T. Group behaviour therapy programmes for smoking cessation. Cochrane Database Syst Rev. 2017;3:CD001007.

13. Becoña E, Míguez MC. Group behavior therapy for smoking cessation. J Groups Addict Recover. 2008;3(1-2):63-78. https://doi.org/10.1080/155603 50802157528.

14. McClure JB, Bricker J, Mull K, Heffner JL. Comparative effectiveness of groupdelivered acceptance and commitment therapy versus cognitive behavioral therapy for smoking cessation: a randomized controlled trial. Nicotine Tob Res. 2020;22(3):354-62. https://doi.org/10.1093/ntr/nty268.

15. Carlson LE, Goodey E, Bennett MH, Taenzer P, Koopmans J. The addition of social support to a community-based large-group behavioral smoking cessation intervention: improved cessation rates and gender differences. Addict Behav. 2002; 27(4):547-59. https//doi.org/10.1016/50306-4603(01)00192-7.

16. Zheng P, Guo F, Chen Y, Fu Y, Ye T, Fu H. A randomized controlled trial of group intervention based on social cognitive theory for smoking cessation in China. J Epidemiol. 2007;17(5):147-55. https://doi.org/10.2188/jea.17.147.

17. Itumalla R, Aldhmadi B. Combating tobacco use in Saudi Arabia: a review of recent initiatives. East Mediterr Health J. 2020;26(7):858-63. https://doi.org/1 0.26719/emhj.20.019.

18. Alsamghan AS. Quitting smoking: experiences from the southwestern region, Saudi Arabia; 2018

19. Moradi-Lakeh M, El Bcheraoui C, Tuffaha M, Daoud F, Al Saeedi M, Basulaiman M, et al. Tobacco consumption in the Kingdom of Saudi Arabia, 2013: findings from a national survey. BMC Public Health. 2015;15(1):1-10.

20. de Zwart KM, Sellman JD. Public knowledge and attitudes regarding smoking and smoking cessation treatments. N Z Med J. 2002;115(1153):219-22.

21. Cor I. IBM SPSS statistics for windows, version 24.0. Armonk: IBM Corp; 2016.

22. Gunay T, Pekel O, Simsek H, Sahan C, Soysal A, Kilinc O, et al. Smoking habits and cessation success. Saudi Med J. 2014;35(6):585-91.

23. Mahdi HA, Elmorsy SA, Melebari LA, Al-Masudi SM, Sharbini DA, Najjar AG, et al. Prevalence and intensity of smoking among healthcare workers and their attitude and behavior towards smoking cessation in the western region of Saudi Arabia: a cross-sectional study. Tob Prev Cessat. 2018; 4(August). https://doi.org/10.18332/tpc/93787.

24. Figueiró LR, Barros HMT, Ferigolo M, Dantas DCM. Assessment of factors related to smokers' adherence to a short-term support group for smoking cessation: a longitudinal study in a developing country. Trends Psychiatry Psychother. 2017;39(1):19-28. https://doi.org/10.1590/2237-6089-2016-0041.

25. Alotaibi SA, Alsuliman MA, Durgampudi PK. Smoking tobacco prevalence among college students in the Kingdom of Saudi Arabia: systematic review and metaanalysis. Tob Induc Dis. 2019;17(April). https://doi.org/10.18332/tid/105843.

26. Bassiony MM. Smoking in Saudi Arabia. Saudi Med J. 2009;30(7):876-81.

27. Mohammed M, Eggers SM, Alotaiby FF, de Vries N, de Vries H. Effects of a randomized controlled trial to assess the six-months effects of a school based smoking prevention program in Saudi Arabia. Prev Med. 2016;90:1006. https://doi.org/10.1016/j.ypmed.2016.06.032.

28. Saeed A, Khoja TA, Khan SB. Smoking behaviour and attitudes among adult Saudi nationals in Riyadh City, Saudi Arabia. Tob Control. 1996;5(3):215-9. https://doi.org/10.1136/tc.5.3.215.

29. Zhou X, Nonnemaker J, Sherrill B, Gilsenan AW, Coste F, West R. Attempts to quit smoking and relapse: factors associated with success or failure from the ATTEMPT cohort study. Addict Behav. 2009;34(4):365-73. https://doi.org/10.1 016/j.addbeh.2008.11.013.

30. Bacha ZA, Layoun N, Khayat G, Hallit S. Factors associated with smoking cessation success in Lebanon. Pharm Pract (Granada). 2018;16(1):1111.

31. Chen D, Wu L-T. Smoking cessation interventions for adults aged 50 or older: a systematic review and meta-analysis. Drug Alcohol Depend. 2015; 154:14-24. https://doi.org/10.1016/j.drugalcdep.2015.06.004.

32. Cropsey K, Eldridge G, Weaver M, Villalobos G, Stitzer M, Best A. Smoking cessation intervention for female prisoners: addressing an urgent public health need. Am J Public Health. 2008;98(10):1894-901. https://doi.org/10.2105/AJPH.2007.128207.

33. Siddiqui S, Ogbeide DO. Profile of smoking amongst health staff in a primary care unit at a general hospital in Riyadh, Saudi Arabia. Saudi Med J. 2001;22(12):1101-4.

\section{Publisher's Note}

Springer Nature remains neutral with regard to jurisdictional claims in published maps and institutional affiliations. 